\title{
Impact of insulins glulisine and aspart on postprandial glycemia after a high-glycemic index meal in children with type 1 diabetes
}

\author{
Katarzyna Dżygało and Agnieszka Szypowska \\ Department of Paediatrics, Medical University of Warsaw, Dzialdowska 1, 01-184 Warsaw, Poland
}

\author{
Correspondence \\ should be addressed \\ to A Szypowska \\ Email \\ agnieszka.szypowska@ \\ gmail.com
}

\begin{abstract}
Objective: According to current knowledge, glulisine insulin (GLU) has a slightly faster onset of action than aspart (ASP) insulin. Therefore, GLU might lead to a better postprandial profile than ASP following the consumption of high-glycemic index $(\mathrm{H}-\mathrm{Gl})$ meals. The aim of this study was to assess differences in the action of GLU and ASP after the consumption of a $\mathrm{H}-\mathrm{GI}$ meal in type 1 diabetic children treated with insulin pumps.

Design: Fifty-six type 1 diabetic children of mean age $14.7 \pm 2.0$ years were included in a randomized, double-blind, two-way crossover study. The subjects were allocated to one of two treatment orders: GLU-ASP and ASP-GLU. They were given a H-GI breakfast for two subsequent days.

Methods: The primary outcome was postprandial glycemia (PPG) based on continuous glucose monitoring system and self monitoring of blood glucose levels during $3 \mathrm{~h}$ of follow-up. The secondary outcomes were the frequency of hypoglycemia, glucose area under the curve, mean amplitude of glycemic excursion, and glycemic rise.

Results: There were no significant differences between the groups with regard to PPG in the determined time intervals as well as with respect to the secondary outcomes. Between 60 and $120 \mathrm{~min}$ after food consumption in both study groups, blood glucose levels were close to or above $10.0 \mathrm{mmol} / \mathrm{l}$. Glucose peaks were higher in the GLU-ASP group than in the ASP-GLU group (90 min: $P=0.065 ; 120 \mathrm{~min}: P=0.052$ ). Most of the episodes of hypoglycemia were observed after the second hour of follow-up.
\end{abstract}

Conclusions: No statistically significant difference was found between GLU and ASP with regard to PPG after the consumption of a H-GI breakfast. Neither GLU nor ASP stabilized the glycemic profile after the consumption of a $\mathrm{H}-\mathrm{Gl}$ meal.

European Journal of

Endocrinology

(2014) 170, 539-545

\section{Introduction}

The major determinant of $\mathrm{HbA1c}$ is postprandial glycemia (PPG). Postprandial glucose deviations cause glucose toxicity and accelerate the progression of diabetic complications. It has been confirmed that postprandial hyperglycemia is an independent risk factor for macrovascular diseases and may occur even when overall metabolic control seems to be appropriate on the basis of
HbA1c levels (1). Therefore, one of the main contributing factors of a stable glycemic profile is the reduction of postprandial glucose levels. It is particularly difficult to maintain tight glycemic control after the consumption of high-glycemic index (H-GI) meals. Due to rapid absorption, H-GI foods cause a high increase in glucose levels, with the highest peak being observed in the first
(ㄷ) 2014 European Society of Endocrinology Printed in Great Britain
Published by Bioscientifica Ltd. 
hour after meal consumption followed by a decrease in glucose levels in the second hour after consumption (2). Despite the fact that H-GI products are not recommended for people with diabetes, children prefer eating them.

Clinical studies have shown that all rapid-acting insulin analogs (aspart, lispro, and glulisine) provide better postprandial control than regular human insulin (3). However, the most recent data indicate that there might be some subtle differences between these analogs. Due to the absence of hexamer-promoting zinc, glulisine insulin (GLU) has been shown to have earlier onset of action, faster absorption, and significantly higher metabolic effect compared with lispro insulin and aspart insulins (ASP) $(4,5,6)$. Considering these facts, we hypothesized that GLU should lead to a better postprandial profile than ASP after the consumption of H-GI meals. Although there are a few studies that have compared the properties of rapid-acting insulin analogs in adults $(7,8,9,10)$, the number of studies in a pediatric population is still limited $(10,11)$.

The objective of this study was to determine whether GLU is more effective than ASP with regard to postprandial glycemic control after the consumption of a H-GI meal in children with type 1 diabetes mellitus (T1DM) treated with continuous subcutaneous insulin infusion (CSII).

\section{Subjects and methods}

This was a prospective, randomized, double-blind, crossover controlled study conducted between September 2011 and September 2012 in the Department of Paediatrics at the Medical University of Warsaw, Poland. The study was carried out according to the guidelines of the CONSORT statement (12). The study included teenagers aged between 10 and 18 years with T1DM for at least 1 year who were treated with CSII for at least 3 months and used the same insulin analog for at least 3 months before study entry. Exclusion criteria were the following: remission phase defined as daily insulin dose $<0.5 \mathrm{unit} / \mathrm{kg}$ of body mass per $24 \mathrm{~h}$, concomitant dietary restrictions (e.g. celiac disease or food allergy), diabetes-related complications, and any disease judged by the investigator to affect the trial. To be randomized, the participants had to have no blood glucose fluctuations $3 \mathrm{~h}$ before study entry based on continuous glucose monitoring system (CGMS) values, fasting glycemia with a value between 70 and $150 \mathrm{mg} / \mathrm{dl}$ (3.9-8.3 mmol/l) on both study days, and no correction boluses for at least $3 \mathrm{~h}$ before test meal consumption. The study was approved by the Ethics Committee of the Medical University of Warsaw. Written consent was obtained from the caregivers and patients older than 16 years before inclusion in the study. Verbal consent was obtained from all subjects.

The subjects were randomized to two treatment schemes using a block randomization process with a block size of six, unknown to the investigator. A randomization list was generated by a computer program and kept by a staff member not involved in the study. Preparation of the study medications and refilling of insulin infusion set were controlled by nurses who were not involved in the study. In the afternoon before each study day, the whole pump site (including cartridge and catheter) and the type of insulin were changed. Only steel needle sets were used. Both the tested insulins, glulisine (Apidra; Sanofi, Paris, France) and aspart (NovoRapid; Novo Nordisk, Bagsvaerd, Denmark), are clear and colorless, so neither the patients nor the investigator were aware of the kind of insulin used. A new sensor (Sof-Sensor, Medtronic) for CGMS using the Guardian RT or Paradigm 722 system (Medtronic MiniMed, Northridge, CA, USA) was inserted in the afternoon before a 2-day study block. There is no difference between these two devices with regard to calibration algorithm. Participants who met the inclusion criteria were randomly assigned to two groups: ASP-GLU group, consisting of patients who received ASP on the first day of the trial and GLU on the second day, and GLU-ASP group, consisting of patients who received GLU on the first day of the trial and ASP on the second day.

There were 64 children included, aged 14.6 years, on average (10.3-17.9), 31 boys and 33 girls, with mean diabetes duration of 4.9 years and mean HbA1c of $8.6 \%$ $(70 \mathrm{mmol} / \mathrm{mol})$. The subjects remained hospitalized for the whole study period. HbA1c value was obtained just before study entry using HPLC, with the normal range $4.1-6.4 \% \quad(21-46 \mathrm{mmol} / \mathrm{mol})$ for subjects without diabetes. The level of HbA1c was not a limitation for the randomization. Teenagers with blood glucose fluctuations based on data from home diaries were admitted to the hospital for at least 1 week before study entry to normalize basal insulin rate and insulin-to-carbohydrate ratios (ICRs) according to the International Society for Pediatric and Adolescent Diabetes (ISPAD) recommendations. Insulin doses were calculated based on the self-monitoring of blood glucose (SMBG) nine-point profile. During hospitalization, all children were under the strict control of the diabetological team (meals were prepared by dietitians, each child had a nine-point glucose profile performed by nurses, and insulin doses were adjusted by diabetologists). 
Activity was limited to sedentary activities in a research unit under comparable conditions.

The subjects were given a H-GI breakfast for two subsequent days, containing $50 \mathrm{~g}$ of carbohydrates $(\mathrm{CHO})$ from corn flakes and $10 \mathrm{~g}$ from $2 \%$ fat milk. Two participants refused to eat such large portions and therefore were given a study meal containing $40 \mathrm{~g}$ of $\mathrm{CHO}$.

The participants used their own ICR, and the dose of insulin was constant over the study period. Pre-breakfast insulin was given as a standard bolus $15 \mathrm{~min}$ before meal consumption. A waiting period of $15 \mathrm{~min}$ was included in the protocol due to the onset of action of rapid-acting insulin analogs to optimize insulin administration. Meals were consumed in the morning about $0800 \mathrm{~h}$ in their entirety within $15 \mathrm{~min}$. The subjects were instructed not to consume any additional meal, snacks, etc. and were not given any correction boluses $3 \mathrm{~h}$ before each test meal and $3 \mathrm{~h}$ of the study period.

Capillary blood glucose levels (SMBG) were measured using Contour TS meter (Bayer HealthCare LLC) in fasted subjects before breakfast, every $30 \mathrm{~min}$ for the first $2 \mathrm{~h}$, and finally once after $3 \mathrm{~h}$ of starting of the test. Additional measurements were taken if patients reported symptoms of hypoglycemia. Hypoglycemia was defined as glucose concentration below $65 \mathrm{mg} / \mathrm{dl}(3.3 \mathrm{mmol} / \mathrm{l})$ with or without symptoms (13). If glycemia was lower than $65 \mathrm{mg} / \mathrm{dl}(3.3 \mathrm{mmol} / \mathrm{l})$ at any time point during the first $3 \mathrm{~h}$ after breakfast consumption, the patients were given $10-20 \mathrm{~g}$ of $\mathrm{CHO}$.

We expected rapid postmeal fluctuations in blood glucose values. During a rapid rate of change in glucose levels, CGMS values might be different from SMBG values because CGMS measures glucose levels in the subcutaneous tissue and not in the blood. To obtain the highest accuracy of glycemic values at a specific time point, we decided to use SMBG as a primary outcome.

The primary outcome was defined as PPG assessed 30, $60,90,120$, and $180 \mathrm{~min}$ after meal bolus consumption (six-point glucose curve).

The secondary outcomes were the following: hypoglycemic episodes, mean amplitude of glycemic excursion (MAGE) and glycemic rise (GR), and glucose area under the curve (AUC).

\section{Statistical analysis}

Estimation of the sample size was based on the primary outcome (PPG). We expected to detect a difference in PPG of $30 \mathrm{mg} / \mathrm{dl}(1.7 \mathrm{mmol} / \mathrm{l})$ with $\alpha=0.05$. A total of 63 participants were needed to achieve a statistical power of $80 \%$ assuming a $20 \%$ withdrawal rate. Sample size calculation was performed using StatsDirect (StatsDirect Ltd., England, UK).

Variables were analyzed on per-protocol basis, including all participants who completed the trial and complied with their allocated intervention.

Comparisons between the groups were made using Student's $t$-test (unpaired, two-tailed) or, in case of nonparametric data, with the Mann-Whitney $U$ test or Fisher's exact test. Odds ratio (OR) was calculated with 95\% CIs. Factorial ANOVA was used to assess the effect of sequence. Differences between the study groups were considered significant when $P$ value was $<0.05$.

GR (delta) was defined as the difference between maximal blood glucose (from SMBG) level during the test and basal glucose value.

AUC was estimated using the trapezoidal rule (14) data from the CGMS. AUC was defined as the sum of absolute values of excursions from the sensor at the start and was calculated for a 3-h period following each meal and bolus combination. Incremental AUC (iAUC) was calculated by subtracting basal value from sample points below integrating AUC. Positive AUC (pAUC) was computed in two steps: estimations of intersection points of the estimated curve with baseline and integration of the area above baseline. The analysis was carried out using Statistica 10 (StatSoft, Inc., Tulsa, OK, USA) software.

\section{Results}

Of the 64 children who were randomized, 33 were assigned to the GLU-ASP study arm and 31 were assigned to the ASP-GLU arm (Fig. 1). Seven children withdrew from the study during follow-up. Finally, data of 56 (87.5\%) patients were analyzed based on SMBG. The characteristics of the study subjects are given in Table 1. Data from the CGMS of three subjects were not analyzed due to problems with the sensor (loss of sensor or sensor data). The study took 2-3 days for completion. Most of the patients (91.1\%) completed the study within 2 days. Five (8.9\%) children needed 3 days due to impaired baseline glycemia or a correction bolus before study entry. There were different infusion site locations: abdomen (25\%), upper outer thighs (15\%), buttocks (25\%), and arms (35\%). However, we did not observe any statistical influence of site locations on blood sugar values $(P>0.05)$. All children, except two, consumed $60 \mathrm{~g}$ of $\mathrm{CHO}$ with mean 1.0 s.D. $0.24 \mathrm{~g} / \mathrm{kg}$ of body weight. There were no statistically significant differences between both groups in grams of $\mathrm{CHO}$ per kilogram of body weight $(P=0.401)$. 


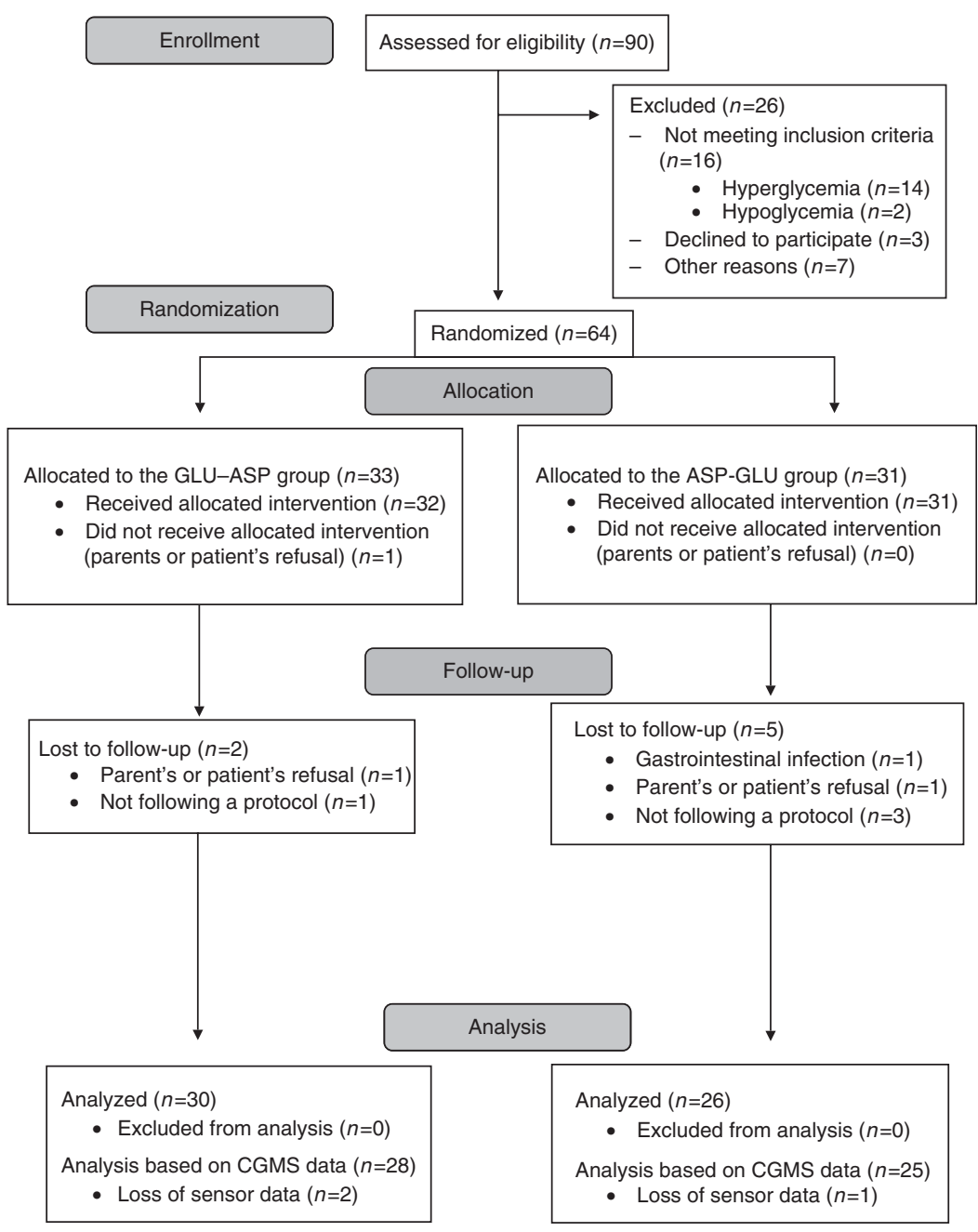

\section{Figure 1}

Flow diagram of participant recruitment.

\section{Postprandial glycemia}

There were no statistically significant differences with regard to the mean PPG between GLU and ASP, at each time interval (Fig. 2). Between 60 and $120 \mathrm{~min}$ after food consumption in both study groups, blood glucose levels were close to or above $180 \mathrm{mg} / \mathrm{dl}(10.0 \mathrm{mmol} / \mathrm{l})$, and glucose peaks were higher in the GLU-ASP group than in the ASP-GLU group, but these differences were close to statistical significance $(90 \mathrm{~min}: P=0.065 ; 120 \mathrm{~min}$ : $P=0.052$ ) (Fig. 2).

\section{Hypoglycemia}

Ten (17.8\%) patients treated with GLU and 11 (19.64\%) patients treated with ASP suffered from hypoglycemia
(<65 mg/dl, $3.3 \mathrm{mmol} / \mathrm{l}$ ) (OR 0.89 (95\% CI: 0.34-2.30); $P=0.809$ ). Most of the hypoglycemic episodes were observed after the second hour of follow-up. No severe hypoglycemia was observed.

\section{Glycemic excursion}

There were no differences between the groups with respect to both iAUC $(P=0.108)$ and pAUC $(P=0.158)$ (Table 2$)$.

No difference was observed between the groups with regard to MAGE, $P=0.309$, and GR (delta), $P=0.275$ (Table 2). No sequence or interaction effect was found.

A subanalysis in an overweight (BMI $\geq 85$ and $<95$ percentiles) and obese (BMI $\geq 95$ ) population (consisting of 15 patients) revealed no statistically significant 
Table 1 Characteristics of the study subjects. Data are given as means \pm s.D. (range).

\begin{tabular}{l}
\hline \\
\hline Female/male $(n)$ \\
Age (years) \\
BMI (kg/m²) \\
BMI percentile \\
BMI SDS LMS \\
Diabetes duration (years) \\
Pump treatment duration \\
(years) \\
HbA1c $(\%)$ \\
HbA1c (mmol/mol) \\
Insulin (IU/kg) \\
Percentage of basal insulin \\
of total daily dose (\%)
\end{tabular}

\begin{tabular}{|c|c|}
\hline ASP-GLU $(n=26)$ & ALL $(n=56)$ \\
\hline $\begin{array}{c}8 / 18 \\
14.6 \pm 2.0 \\
21.4 \pm 3.7(16.8-31.0) \\
61.5 \pm 27.1(6.0-98.0) \\
0.4 \pm 0.97(-1.67 \text { to } 2.36) \\
5.6 \pm 3.2 \\
4.3 \pm 2.3\end{array}$ & $\begin{array}{c}29 / 27 \\
14.7 \pm 2.0 \\
22.1 \pm 3.1(16.8-31.0) \\
68.2 \pm 23.5(6.0-98.0) \\
0.62 \pm 0.82(-1.67 \text { to } 2.36) \\
5.0 \pm 3.1 \\
3.8 \pm 2.3\end{array}$ \\
\hline $\begin{array}{c}9.2 \pm 2.2(6.0-11.5) \\
76.88 \pm 24.4(42.1-102.2) \\
0.85 \pm 0.1 \\
34.9 \pm 9.4(19.7-61.1)\end{array}$ & $\begin{array}{c}8.6 \pm 1.8(6.0-11.6) \\
70.6 \pm 20.7(42.1-103.3) \\
0.85 \pm 0.2 \\
34.4 \pm 9.8(8.8-61.1)\end{array}$ \\
\hline
\end{tabular}

differences in PPG, MAGE, pAUC and iAUC, GR, and episodes of hypoglycemia ( $P>0.05$ for all outcomes).

\section{Discussion}

To the best of our knowledge, this is the first study to evaluate the efficacy of GLU in comparison with ASP with respect to PPG after the consumption of H-GI foods in type 1 diabetic children treated with insulin pumps. The present study demonstrated similar postprandial glycemic control of both GLU and ASP after the consumption of a H-GI breakfast in pump users. Our findings are consistent with results obtained by other authors (11). We did not observe any statistical difference between both insulins with regard to postprandial glycemic excursion during the 3-h period of follow-up. Although glucose peaks in the first and second hour after food consumption were higher in the GLU-ASP group than in the ASP-GLU group, these differences were only close to statistical significance. In the study carried out by Cemeroglu et al. (11) comparing GLU and ASP in prepubertal type 1 diabetic children treated with multiple daily injections, the authors demonstrated that postprandial excursions in the second and fourth hour were higher for GLU than for ASP.

Hypoglycemia is a common adverse effect of dosing insulin before the consumption of H-GI foods. We did not observe any significant differences in the incidence of hypoglycemia between the groups. Although the incidence of hypoglycemia at the 2- and 4-h postprandial time points was similar for both GLU and ASP, an insignificant trend toward a higher incidence of hypoglycemia was observed in the ASP-GLU group. These findings are consistent with those presented by Cemeroglu et al. (11). The authors showed significantly more hypoglycemic events 2 and $4 \mathrm{~h}$ after H-GI food ingestion with ASP than

with GLU. The results of other studies assessing the safety and efficacy of GLU in comparison with other insulin analogs are inconclusive; some authors have reported a greater incidence of hypoglycemia with GLU (9), while others have not confirmed this observation $(3,10)$. In a study comparing GLU, ASP, and lispro insulin in adults with T1DM using CSII, despite a lack of differences in the reported incidence of hypoglycemia, the overall rate of hypoglycemia $(<70 \mathrm{mg} / \mathrm{dl})$ per patient-year was significantly higher for GLU than for ASP (15).

Children tend to consume H-GI meals, especially during breakfast time. They often choose corn flakes with milk. As shown in healthy subjects, dairy products (mainly milk) stimulate higher insulin response despite a low GI.

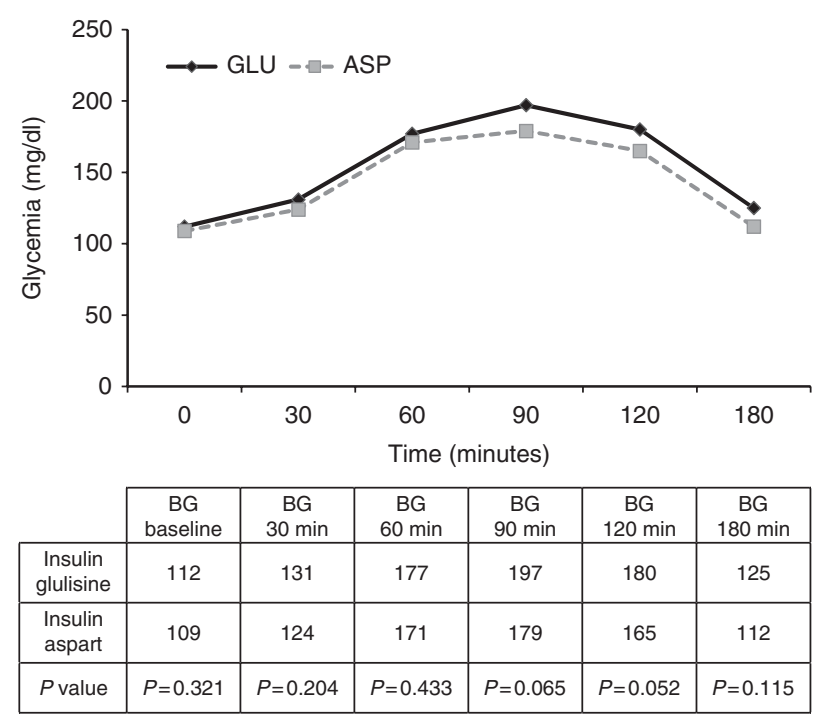

${ }^{*} \mathrm{BG}=$ blood glucose $(\mathrm{mg} / \mathrm{dl})$

Figure 2

Mean postprandial glycemia. 
Table 2 Secondary outcomes. Data are given as means \pm s.D.

\begin{tabular}{|c|c|c|c|}
\hline & GLU & ASP & $P$ values \\
\hline Glycemic rise & & & 0.275 \\
\hline$(\mathrm{mg} / \mathrm{dl})$ & $97.5 \pm 61.9$ & $86.0 \pm 47.9$ & \\
\hline$(\mathrm{mmol} / \mathrm{l})$ & $5.41 \pm 3.4$ & $4.77 \pm 2.6$ & \\
\hline $\mathrm{pAUC}(\min \times \mathrm{mg} / \mathrm{dl})$ & $7977 \pm 5535$ & $6704 \pm 6201$ & 0.108 \\
\hline iAUC $(\min \times \mathrm{mg} / \mathrm{dl})$ & $7260 \pm 881$ & $6092 \pm 934$ & 0.158 \\
\hline MAGE & & & 0.309 \\
\hline (mg/dl) & $67.4 \pm 26.5$ & $62.7 \pm 21.6$ & \\
\hline$(\mathrm{mmol} / \mathrm{l})$ & $3.7 \pm 1.5$ & $3.5 \pm 1.2$ & \\
\hline Hypoglycemia (n(\%)) & $10(17.8 \%)$ & $11(19.6 \%)$ & 0.809 \\
\hline
\end{tabular}

pAUC, positive area under the curve (AUC); iAUC, incremental AUC; MAGE, mean amplitude of glycemic excursions.

Responsible for this situation is not only lactose, but also milk proteins, which have insulinotropic properties (16). Some studies indicate that the meal fiber content (17) and GI $(17,18)$ do not influence the bolus dosing. However, other authors recommend the use of a higher ICR for H-GI foods to reduce postprandial hyperglycemia (19). According to the ISPAD recommendations for glucose targets, optimal PPG should be under $180 \mathrm{mg} / \mathrm{dl}$ (10.0 mmol/l) (20). The results of the present study revealed that mean PPG between 60 and 120 min after food consumption in both study groups was close to or above the target range/limit. However, the subjects achieved near-normal glycemia in the third hour without additional correction boluses. As shown in other studies, consuming H-GI meals is associated with a higher risk of hypoglycemia $(21,22,23)$. In healthy subjects, H-GI meals result in a rapid increase in blood glucose and insulin levels followed by reactive hypoglycemia. The high percentage of hypoglycemia in both our study groups after H-GI meal consumption confirms the results reported by other authors. Patients included in the present study had no hypoglycemia after daily breakfast consumption within at least 3 days before study entry. Moreover, they had constant individual pump settings during both study days. Therefore, both ICRs and pump settings should not have any influence on the rate of hypoglycemia.

Some authors have concluded that both hyperglycemia at fasting and during postprandial periods and acute glucose fluctuations activate protein glycation and induce oxidative stress. Both of these metabolic alterations contribute to the complications of diabetes. Therefore, fluctuations in blood glucose levels should be taken into consideration while assessing the risk of late complications of diabetes $(14,24)$. In the present study, we observed postprandial glucose fluctuations in both groups, using GLU and ASP, although without any statistical difference in variation in glucose levels.
A potential limitation of this study was related to the fact that two subjects refused to consume $60 \mathrm{~g}$ of the test meal. They consumed $40 \mathrm{~g}$ of $\mathrm{CHO}$; the glycemic index remained the same, but the glycemic load was lower. However, they were not excluded from the study due to the crossover design of the trial. We did not observe any statistical differences in grams of $\mathrm{CHO}$ per kilogram of body weight between the study groups. In comparison, in the study carried out by Cemeroglu et al. (11), the subjects ingested different types of products (with a similar GI) with 45,60 , or $75 \mathrm{~g}$ of $\mathrm{CHO}$, so the glycemic load was even more unstable.

\section{Conclusions}

In summary, the results of the present study indicate that GLU provides similar postprandial glycemic control as ASP after H-GI food consumption. Neither GLU nor ASP stabilized the glycemic profile after the consumption of a H-GI meal. Therefore, low-GI foods should be consumed to avoid glucose fluctuations.

\section{Declaration of interest}

Sanofi Aventis and Novo Nordisk sponsored A Szypowska and K Dżygało for their lectures as well as participation in medical conferences. There is no conflict of interest that could be perceived as prejudicing the impartiality of the research reported.

\section{Funding}

This study was funded by the Medical University of Warsaw, Poland.

\section{References}

1 Boland E, Monsod T, Delucia M, Brandt CA, Fernando S \& Tamborlane WV. Limitations of conventional methods of selfmonitoring of blood glucose: lessons learned from 3 days of continuous glucose sensing in pediatric patients with type 1 diabetes. Diabetes Care 200124 1858-1862. (doi:10.2337/diacare.24.11.1858)

2 Nilsson A, Radeborg K \& Bjorck I. Effects on cognitive performance of modulating the postprandial blood glucose profile at breakfast. European Journal of Clinical Nutrition 201266 1039-1043. (doi:10.1038/ ejcn.2012.80)

3 Danne T, Becker RH, Heise T, Bittner C, Frick AD \& Rave K. Pharmacokinetics, prandial glucose control, and safety of insulin glulisine in children and adolescents with type 1 diabetes. Diabetes Care 200528 2100-2105. (doi:10.2337/diacare.28.9.2100)

4 Heise T, Nosek L, Spitzer H, Heinemann L, Niemoeller E, Frick AD \& Becker RHA. Insulin glulisine: a faster onset of action compared with insulin lispro. Diabetes, Obesity \& Metabolism 20079 746-753. (doi:10.1111/j.1463-1326.2007.00746.x)

5 Arnolds S, Rave K, Hovelmann U, Fischer A, Sert-Langeron C \& Heise T. Insulin glulisine has a faster onset of action compared with insulin aspart in healthy volunteers. Experimental and Clinical Endocrinology \& Diabetes 2010118 662-664. (doi:10.1055/s-0030-1252067) 
6 Morrow L, Muchmore DB, Hompesch M, Ludington EA \& Vaughn DE. Comparative pharmacokinetics and insulin action for three rapid-acting insulin analogs injected subcutaneously with and without hyaluronidase. Diabetes Care 201336 273-275. (doi:10.2337/dc12-0808)

7 Kawamori R, Kadowaki T, Ishii H, Iwasaki M \& Iwamoto Y. Efficacy and safety of insulin glulisine in Japanese patients with type 1 diabetes mellitus. Diabetes, Obesity \& Metabolism 200911 891-899. (doi:10.1111/ j.1463-1326.2009.01086.x)

8 Dreyer M, Prager R, Robinson A, Busch K, Ellis G, Souhami E \& Van Leendert R. Efficacy and safety of insulin glulisine in patients with type 1 diabetes. Hormone and Metabolic Research 200537 702-707. (doi:10.1055/s-2005-870584)

9 Hoogma RP \& Schumicki D. Safety of insulin glulisine when given by continuous subcutaneous infusion using an external pump in patients with type 1 diabetes. Hormone and Metabolic Research 200638 429-433. (doi:10.1055/s-2006-944549)

10 Philotheou A, Arslanian S, Blatniczky L, Peterkova V, Souhami E \& Danne T. Comparable efficacy and safety of insulin glulisine and insulin lispro when given as part of a Basal-bolus insulin regimen in a 26-week trial in pediatric patients with type 1 diabetes. Diabetes Technology \& Therapeutics 201113 327-334. (doi:10.1089/dia.2010.0072)

11 Cemeroglu AP, Kleis L, Wood A, Parkes C, Wood MA \& Davis AT. Comparison of the effect of insulin glulisine to insulin aspart on breakfast postprandial blood glucose levels in children with type 1 diabetes mellitus on multiple daily injections. Endocrine Practice 2013 19 614-619. (doi:10.4158/EP12399.OR)

12 Schulz KF, Altman DG \& Moher D. CONSORT 2010 statement: updated guidelines for reporting parallel group randomised trials. BMJ 2010340 c332. (doi:10.1136/bmj.c332)

13 Clarke W, Jones T, Rewers A, Dunger D \& Klingensmith GJ. ISPAD clinical practice consensus guidelines 2009 compendium. Assessment and management of hypoglycemia in children and adolescents with diabetes. Pediatric Diabetes 200910 (Suppl 12) 134-144. (doi:10.1111/ j.1399-5448.2009.00583.x)

14 Le Floch JP, Escuyer P, Baudin E, Baudon D \& Perlemuter L. Blood glucose area under the curve. Methodological aspects. Diabetes Care 199013 172-175. (doi:10.2337/diacare.13.2.172)

15 van Bon AC, Bode BW, Sert-Langeron C, DeVries JH \& Charpentier G. Insulin glulisine compared to insulin aspart and to insulin lispro administered by continuous subcutaneous insulin infusion in patients with type 1 diabetes: a randomized controlled trial. Diabetes Technology \& Therapeutics 201113 607-614. (doi:10.1089/dia.2010.0224)

16 Nilsson M, Stenberg M, Frid AH, Holst JJ \& Bjorck IM. Glycemia and insulinemia in healthy subjects after lactose-equivalent meals of milk and other food proteins: the role of plasma amino acids and incretins. American Journal of Clinical Nutrition 200480 1246-1253.

17 Rabasa-Lhoret R, Garon J, Langelier H, Poisson D \& Chiasson JL. Effects of meal carbohydrate content on insulin requirements in type 1 diabetic patients treated intensively with the basal-bolus (ultralenteregular) insulin regimen. Diabetes Care 199922 667-673. (doi:10.2337/ diacare.22.5.667)

18 Franz MJ. The glycemic index: not the most effective nutrition therapy intervention. Diabetes Care 200326 2466-2468. (doi:10.2337/diacare. 26.8.2466)

19 Szypowska A, Pankowska E \& Lipka M. Guidelines concerning insulin dosage in children and adolescents with type 1 diabetes on continuous subcutaneous insulin infusion. Endokrynologia, Diabetologia i Choroby Przemiany Materii Wieku Rozwojowego 200612 45-50.

20 Rewers M, Pihoker C, Donaghue K, Hanas R, Swift P \& Klingensmith GJ. Assessment and monitoring of glycemic control in children and adolescents with diabetes. Pediatric Diabetes 200910 (Suppl 12) 71-81. (doi:10.1111/j.1399-5448.2009.00582.x)

21 Giacco R, Parillo M, Rivellese AA, Lasorella G, Giacco A, D’Episcopo L \& Riccardi G. Long-term dietary treatment with increased amounts of fiber-rich low-glycemic index natural foods improves blood glucose control and reduces the number of hypoglycemic events in type 1 diabetic patients. Diabetes Care 200023 1461-1466. (doi:10.2337/ diacare.23.10.1461)

22 Gilbertson HR, Brand-Miller JC, Thorburn AW, Evans S, Chondros P \& Werther GA. The effect of flexible low glycemic index dietary advice versus measured carbohydrate exchange diets on glycemic control in children with type 1 diabetes. Diabetes Care 200124 1137-1143. (doi:10.2337/diacare.24.7.1137)

23 Niwano Y, Adachi T, Kashimura J, Sakata T, Sasaki H, Sekine K, Yamamoto S, Yonekubo A \& Kimura S. Is glycemic index of food a feasible predictor of appetite, hunger, and satiety? Journal of Nutritional Science and Vitaminology 200955 201-207. (doi:10.3177/jnsv.55.201)

24 Kilpatrick ES, Rigby AS \& Atkin SL. Effect of glucose variability on the long-term risk of microvascular complications in type 1 diabetes. Diabetes Care 200932 1901-1903. (doi:10.2337/dc09-0109)
Received 22 August 2013

Revised version received 10 November 2013

Accepted 10 January 2014 